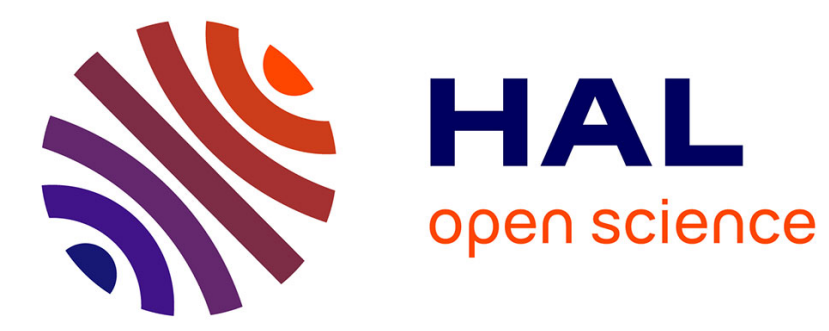

\title{
5G-Ready in the Industrial IoT-Environment
}

Kay Burow, Marco Franke, Klaus-Dieter Thoben

\section{To cite this version:}

Kay Burow, Marco Franke, Klaus-Dieter Thoben. 5G-Ready in the Industrial IoT-Environment. IFIP International Conference on Advances in Production Management Systems (APMS), Sep 2019, Austin, TX, United States. pp.408-413, 10.1007/978-3-030-30000-5_51 . hal-02419263

\section{HAL Id: hal-02419263 \\ https://hal.inria.fr/hal-02419263}

Submitted on 19 Dec 2019

HAL is a multi-disciplinary open access archive for the deposit and dissemination of scientific research documents, whether they are published or not. The documents may come from teaching and research institutions in France or abroad, or from public or private research centers.
L'archive ouverte pluridisciplinaire HAL, est destinée au dépôt et à la diffusion de documents scientifiques de niveau recherche, publiés ou non, émanant des établissements d'enseignement et de recherche français ou étrangers, des laboratoires publics ou privés.

\section{(c)(1)}

Distributed under a Creative Commons Attribution| 4.0 International License 


\title{
5G-Ready in the Industrial IoT-Environment Requirements and Needs for IoT Applications from an Industrial Perspective
}

\author{
Kay Burow ${ }^{1}$, Marco Franke ${ }^{1}$ and Klaus-Dieter Thoben ${ }^{2}$ \\ ${ }^{1}$ BIBA - Bremer Institut für Produktion und Logistik GmbH, Germany \\ ${ }^{2}$ University of Bremen, Institute for Integrated Product Development, Germany \\ bow lbiba . uni-bremen. de
}

\begin{abstract}
.
$5 \mathrm{G}$ will be a key enabler for future trends in the industry 4.0 environment. Two primary goals exist in this context: The first one regards to complex autonomous automation where ultra-high reliability and low latencies are required for the collaboration between humans and robots. The second one will focus on the Internet of Things (IoT), where vast numbers of connected devices (e.g. sensors and actuators) can communicate with each other. Despite all hypes, 5G is still in development, and most details are not clearly defined yet and far beyond the commercial use.

This paper will show an approach for IoT-related usage in an industrial environment by means of its needs, requirements and potentials using the up-coming telecommunication standard $5 \mathrm{G}$.

Especially IoT-applications with hundreds of hundreds of connected devices will support a highly flexible production-logistics system, which can satisfy the actual customer needs for custom-tailored solutions, services and products.

Finally, as a use case, a demonstrator is shown, which will focus on IoT applications in a future production-logistics environment by using a $5 \mathrm{G}$ framework supporting the ideas of Industry 4.0.
\end{abstract}

Keywords: 5G-Ready, Flexible Production Systems, IoT

\section{Introduction}

5G is nowadays a well-known and common term, which has the potential to influence many parts of our lifestyle. Scenarios focus on better-customised solutions and services and will take care of new technical abilities in the industrial environment like high autonomous manufacturing or IoT-supporting applications for area-wide networks of facilities and devices supporting remote control. In addition, to enable these highly flexible systems, a seamless collaboration in communication is required with multiple heterogeneous participants [1]. As 5G does not exist as a running system yet, literature research was done to figure out which aspects are of high relevance in a future application. The following section names the primary pillars of the actual development for 
commercial use. In the beginning, it will be more attractive for large enterprises (LE), later on, by using the given services, it shall be applied in small and medium-sized enterprises (SME) to improve existing solutions. Through guaranteed reliability of $>99.999 \%$ and latencies below $5 \mathrm{~ms}$ [2], it will also have a huge impact on the further development of human-robot-collaboration (HRC)-manufacturing or even robot-supported surgery. For private use, autonomous driving, using the benefits of Smart Cities or Media on demand with ultra-HD resolution will improve the living standards enormously [3].

To achieve these objectives, different developments are in progress, namely [3]:

1. emBB (Enhanced Mobile Broadband), which will be used for large broadcast events, e.g. in places of high interest (stadium, festivals) where many participants use these services within a small area or big cities. Highest availability and multiple bandwidths are required to fulfil the needed capacities.

2. URLLC (Ultra Reliable and Low Latency Communications) which will make autonomous driving possible and is a key factor for HRC due to its high reliability and low latency.

3. mMTC (massive Machine Type Communications) we will be primarily used for machine to machine $(\mathrm{m} 2 \mathrm{~m})$ communication, IoT-applications and its devices. These can be used within a Smart City or build the backbone of a Smart Factory.

All three objectives are shown in Fig. 1 aligned with possible use case scenarios by means of their requirements (e.g. enhanced capacity, massive connectivity).

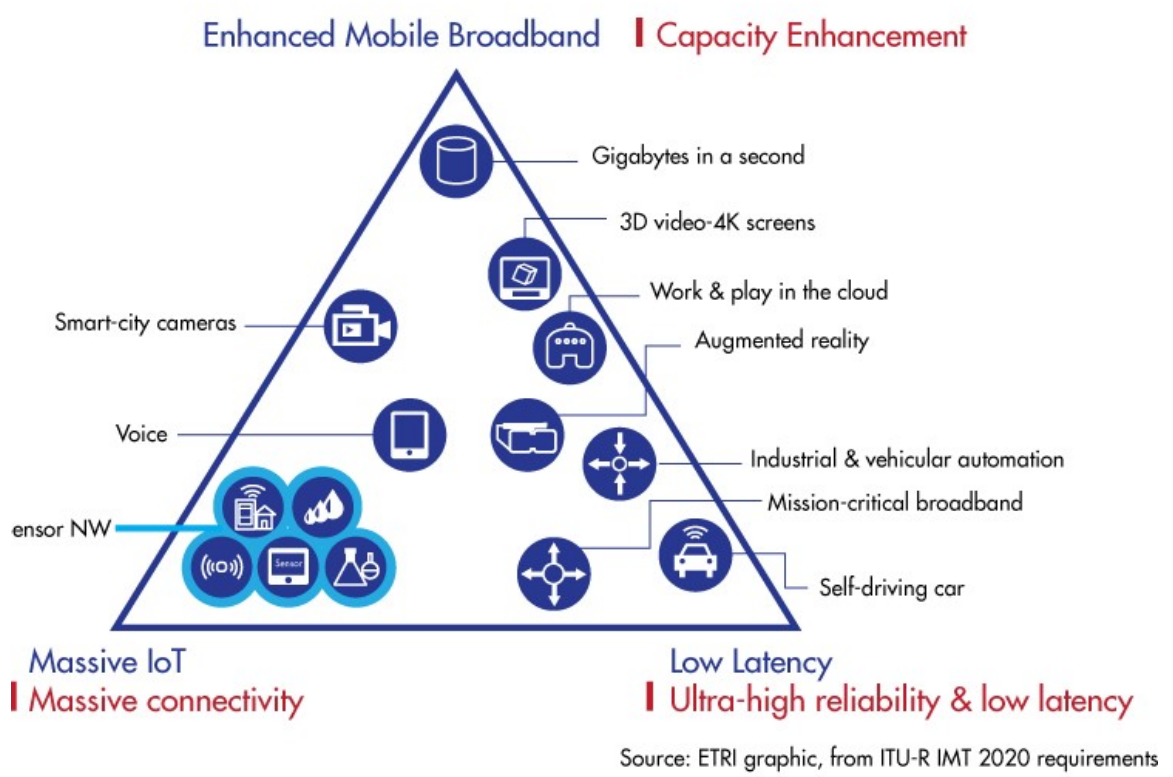

Fig. 1. Distribution of 5G use cases by means of their requirements [4] 
At the moment, the focus of $5 \mathrm{G}$ development mainly lies on emBB with its enhanced capacities for multimedia applications, described in the 3GPP Release 15 [5]. A first trial network was already demonstrated in Seoul during the Winter Olympics in 2018 [6]. MTC and URLLC are mostly developed on the sketch yet, further developments and implementations will be described with the upcoming 3GPP Release 16 at the end of this year [7]. This paper focusses on the industrial environment, especially on mMTC with its IoT-devices and shows, which requirements are necessary to improve the production logistics environment for future connected factories.

\section{Approach}

As already mentioned in the section before, $5 \mathrm{G}$ is far from commercial use, especially using IoT. Therefore, the approach emphasises the provision of requirements for the mMTC of $5 \mathrm{G}$ to ensure its applicability for the integration of IoT in the scope of industry 4.0, which is motivated in the following.

To develop a proper setup, a very close collaboration between the telecommunication providers and the industrial stakeholder exists and is highly required. Here, the telecommunication providers set the framework, architecture and orchestration for the $5 \mathrm{G}$ network, whereas the industrial stakeholders define their needs and technical perspectives [8]. One of these needs are connected, more flexible and decentralised networks for IoT-applications. These applications will normally use IoT related commercial-of-the-shelf (COTS) products such as temperature sensors or simple actuators, which do not need much data traffic; rather their amount of information is limited to a couple of digits.

Nevertheless, it is planned to connect hundreds of devices, their environment and production facilities, which will result in a high density of entities per area. Further, high availability and coverage are required to guarantee a seamless collaboration [9]. This also means that different facilities can be connected to create a flexible cluster on a production site.

Another aspect is that these IoT related entities shall have an extended power duration of up to 10 years per device. To achieve this goal, it is only possible by lower the frequency and narrow bandwidth at a minimum, but still, fulfil a correct data transmission. Through the reduction, less power will be consumed, which results in a longer battery lifetime [8]. For this, a new bandwidth is required and by now not developed. It means in theory, it is there, but the necessary infrastructure for this does not exist yet.

With the background from literature and the demands from the industry to further improvement, a specific research question was deployed, based on the specific background of the institute profile in production and logistics. Of high interest is, which opportunities offer 5G compared to existing, mostly wired, industrial systems, especially with the focus on SMEs.

To change the view to the industrial acceptance of $5 \mathrm{G}$, new services or better service quality are required. Coming from the typical mass production, the modern customer demands specific and individual solutions. Having this in mind, it is clear that by orders on demand, much higher flexibility is required, which should not end up in a mess of 
heterogeneous product variant services. Cloud services are going to provide the needed transparency and accessibility for many. By putting the orders in a cloud and do the computing and data storage there, new services based on $5 \mathrm{G}$ capabilities have to be implemented. For SMEs, this is of high interest because missing services can be purchased. This kind of adaptability enables the idea of a flexible production system (on demand). Moreover, 5G enables the interconnection of different facilities (including the above mentioned IoT devices) in real-time. Thus, a supply chain, which is a compound of multiple SMEs, can be merged virtually. In this case, the compound could react immediately on changing events like changing customer demands, varying product quality or logistical issues. Considering the above-mentioned potential use cases, $5 \mathrm{G}$ is applied as an enabler for the corresponding services that have to be created upon it. To enable the inclusion of product usage data, the provision of predictive maintenance approaches, customizable production processes and the digitisation of supply chains into a future Industry 4.0-environment, the following key requirements, coming from literature and multiple stakeholders, for IoT-applications must be considered [3], [8]:

- R1: Support a high density of devices for mMTC-applications to guarantee its functionality

- R2: Low power consumption to extend the lifetime of IoT-components

- R3: High availability to support flexible and decentralised systems

- R4: Cloud services for storing and handling data to support a high availability

- R5: High reliability to guarantee the (and avoid failures) data transmission, which has an impact on the quality of services

- R6: Flexible bandwidths, which will provide the required data transmission all the time

- R7: Real-time monitoring for a transparent view on the production processes

- R8: Tracking/tracing to fulfil the demands in logistic concepts, especially for realtime monitoring

- R9: Security and safety: by means of industrial usage no external shall have access

\section{Use Case}

After listing the key requirements, a use case based on a production logistics scenario is set up on a low scale for demonstration purpose. With the research question in mind, a test scenario shall be developed with most of the above-mentioned requirements are therefore considered and will be implemented. With a running use case, it will be possible to compare this scenario with common concepts.

The use case itself is based on a simple logistic scenario where a transport box can be tracked and traced, asked about its well-being and analysed delivering goods from one factory to another (Fig.2) one and start from a theoretical perspective. 


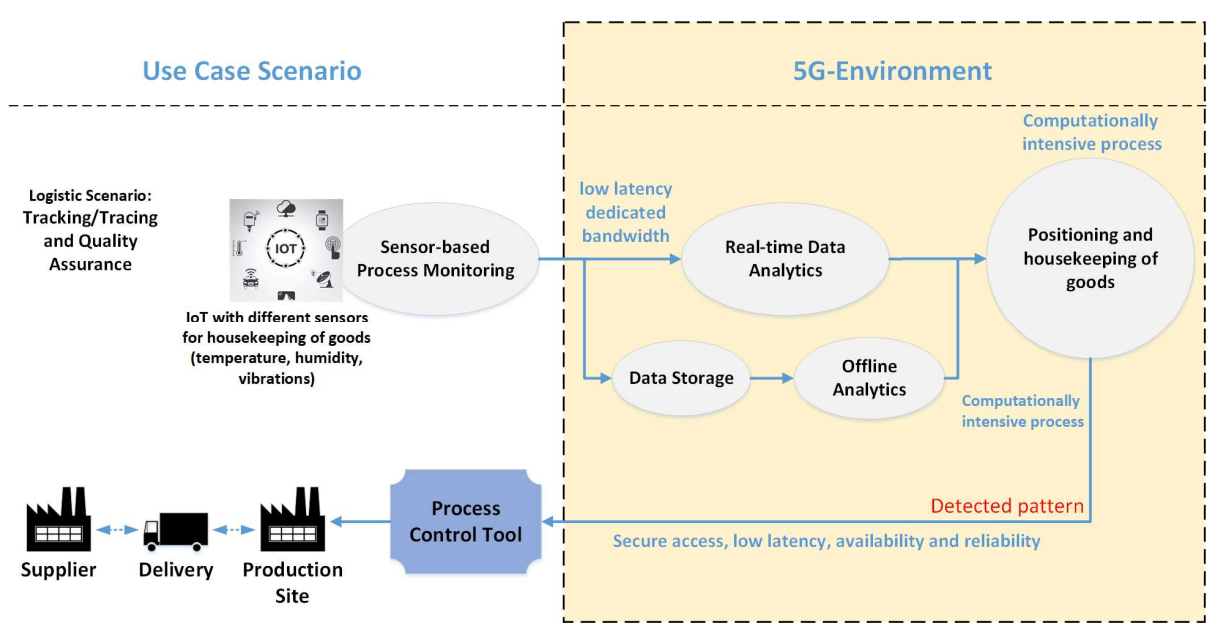

Fig. 2. Use Case depiction via an application graph

Given is a transport box with sensors (temperature, humidity, vibrations, GPS) (R1, $\mathrm{R} 2, \mathrm{R} 3$ ) in it to make the box "smart". The box is connected to a cloud (R4) via an LTEmodule (as a replacement for 5G) where the housekeeping (R5) will be sent continuously. The different distributed cloud service takes the tasks of the data aggregation and the monitoring to enable an automatic condition based monitoring functionality. Critical states or upcoming trends shall be immediately sent to a decision maker. A decision maker could be both a skilled employee and a tool like a PPS. Also, by using a mobile end device (e.g. tablet) (R6), a user can ask for specific data (e.g. temperature, position) directly to receive actual information in almost real-time (R7, R8). Furthermore, only the user will have access to the stored information and analysis results from the cloud services (R9).

Interesting herby is that the $5 \mathrm{G}$ framework will provide computing and orchestration services. The main goal in this use case is to transform the application in a way that it can be used and understood by the $5 \mathrm{G}$ framework. Therefore, it is depicted as an application graph so that the telecommunication providers can see all relevant services that are necessary for this setup.

The use case is still in the development phase, but the authors are eager to start with the testing end of the year. The evaluation will use KPIs to quantise the functional requirements.

\section{Conclusion and Outlook}

It should be clear by now that a running IoT-use case using $5 \mathrm{G}$ is not possible to be set up at the moment. Furthermore, without an existing $5 \mathrm{G}$ infrastructure, no real testing can be done. Nevertheless, the basic needs are described, and with these, the direction of development of the upcoming $5 \mathrm{G}$ standard is clear. Starting with a theoretical use 
case, a test scenario was developed, which uses mostly existing technology (e.g. LTE, $\mathrm{Wi}-\mathrm{Fi}$ ) and will be advanced to $5 \mathrm{G}$ when new components are available.

By showing the use case, the first steps in the Industrial 5G-environment are done. It is a major goal of the authors to continue with this work in the industrial environment as they see huge potentials by connecting independent entities and participants in a cluster for more flexible production on demand in the future. In a distant future, it hopefully will be possible to have a running industrial use case using $5 \mathrm{G}$ to balance its pros, cons and its limits to the existing models.

\section{Acknowledgements}

This work was supported by the European Union's Horizon 2020 research and innovation programme under the MATILDA project under grant agreement No. 761898.

\section{References}

1. Condoluci M, Lema MA, Mahmoodi T et al.: 5G IoT Industry Verticals and Network Requirements. In: Aldmour I, Budiarto R, Mohanan V (eds) Powering the internet of things with $5 \mathrm{G}$ networks, vol 54. IGI Global, Hershey, Pennsylvania (701 E. Chocolate Avenue, Hershey, Pennsylvania, 17033, USA), pp 148175 (2018)

2. Manzalini A SD: A 5G Infrastructure for "Anything-as-a-Service”. J Telecommun Syst Manage 03(02) (2014). doi: 10.4172/2167-0919.1000114

3. Osseiran A, Monserrat JF, Marsch P: 5G Mobile and Wireless Communications Technology // 5G mobile and wireless communications technology. Cambridge University Press, Cambridge, United Kingdom (2014)

4. High-Bands and Horizontal Slicing Challenge 5G (2017). https:/www.mwrf.com/semiconductors/high-bands-and-horizontal-slicing-challenge-5g. Accessed 16 Apr 2019

5. 3GPP Release 15 Overview. https://spectrum.ieee.org/telecom/wireless/3gpprelease-15-overview. Accessed 16 Apr 2019

6. $5 \mathrm{G}$ collaboration in lead up to 2018 winter sporting events (2017). https:/www.ericsson.com/en/news/2017/5/5g-collaboration-in-lead-up-to-2018winter-games. Accessed 10 Apr 2019

7. 3GPP Release 16 (2018). https://www.3gpp.org/release-16. Accessed 16 Apr 2019

8. 5G ACIA. 5G for Connected Industries and Automation (2019), https://www.5g-acia.org/fileadmin/5GACIA/Publikationen/Whitepaper_5G_for_Connected_Industries_and_Automati on/WP_5G_for_Connected_Industries_and_Automation_Download_19.03.19.p df

9. Andrews JG, Buzzi S, Choi W et al.: What Will 5G Be? IEEE J. Select. Areas Commun. 32(6): 1065-1082 (2014). doi: 10.1109/JSAC.2014.2328098 